Published in final edited form as:

Cell Signal. 2014 February ; 26(2): 233-239. doi:10.1016/j.cellsig.2013.11.005.

\title{
Evidence for a regulatory role of Cullin-RING E3 ubiquitin ligase 7 in insulin signallings
}

\author{
Florian Scheufele ${ }^{\# 1}$, Benjamin Wolf ${ }^{\# 1}$, Michael Kruse 2,6 , Thomas Hartmann ${ }^{1}$, Justine \\ Lempart $^{1}$, Susanne Mühlich ${ }^{3}$, Andreas F. H. Pfeiffer ${ }^{2,4}$, Loren J. Field ${ }^{5}$, Maureen J. \\ Charron $^{6}$, Zhen-Qiang Pan ${ }^{7}$, Stefan Engelhardt ${ }^{1,8}$, and Antonio Sarikas ${ }^{1,8,}{ }^{*}$ \\ ${ }^{1}$ Institute of Pharmacology and Toxicology, Technische Universität München, Biedersteiner \\ Straße 29, 80802 Munich, Germany \\ ${ }^{2}$ German Institute of Human Nutrition Potsdam-Rehbrücke, Department of Clinical Nutrition, \\ Arthur-Scheunert-Allee 114-116, 14558 Nuthetal, Germany
}

${ }^{3}$ Walther-Straub-Institute of Pharmacology and Toxicology, Ludwig-Maximilians-University, Goethestraße 33, 80336 Munich, Germany.

${ }^{4}$ Department of Endocrinology, Diabetes and Nutrition, Charité University Medicine, 10117 Berlin, Germany

${ }^{5}$ Krannert Institute of Cardiology, University of Indiana, Indianapolis, IN 46202, USA

${ }^{6}$ Departments of Biochemistry, Medicine (Endocrinology) and Obstetrics \& Gynecology and Women's Health, Albert Einstein College of Medicine, 1300 Morris Park Avenue, Bronx, NY 10461, USA

${ }^{7}$ Mount Sinai School of Medicine, Icahn Medical Institute, Dept. of Oncological Sciences, 1425 Madison Avenue, New York, NY 10029, USA

${ }^{8}$ DZHK (German Center for Cardiovascular Research), partner site Munich Heart Alliance, 80802 Munich, Germany

\# These authors contributed equally to this work.

\begin{abstract}
Dysfunctional regulation of signalling pathways downstream of the insulin receptor plays a pivotal role in the pathogenesis of insulin resistance and type 2 diabetes. In this study we report both in vitro and in vivo experimental evidence for a role of Cullin-RING E3 ubiquitin ligase 7 (CRL7) in
\end{abstract}

\footnotetext{
§Abbreviations: ANOVA, analysis of variance; CUL7, Cullin7; CRL7, Cullin RING E3 ubiquitin ligase 7; FBXW8, F-box/WD repeat-containing protein 8; GLUT4, glucose transporter 4; HSP90, heat shock protein 90; IRS, insulin receptor substrate; IGF-1, insulin-like growth hormone 1; ITT, insulin tolerance test; MAPK, mitogen-activated pathway kinase; MEF, mouse embryonic fibroblast; PI3K, phosphoinositol-3 kinase; RING, really interesting new gene; mTORC, mammalian target of rapamycin, S6K, p70 S6 kinase; UPS, ubiquitin proteasome-system; WT, wild type; 2-DOG, 2-deoxy-D-(3H)-glucose.

(C) 2013 Elsevier Inc. All rights reserved.

*corresponding author. Tel.: +49 (0) 894140 3298, Fax: +49 (0) 894140 3261. sarikas@ ipt.med.tum.de. scheufele@ ipt.med.tum.de (A. Scheufele), bennitto@gmx.de (B. Wolf), michael.kruse@dife.de (M. Kruse),

Hartmann@ipt.med.tum.de (T. Hartmann), justinel@gmx.de (J. Lempart), susanne.muehlich@lrz.uni-muenchen.de (S. Muehlich), afhp@dife.de (A. F. H. Pfeiffer), ljfield@iupui.edu (L. J. Field), maureen.charron@einstein.yu.edu (M. J. Charron), zhenqiang.pan@mssm.edu (Z.-Q. Pan), stefan.engelhardt@tum.de (S. Engelhardt)

Competing interest statement The authors declare no competing financial interests.

Publisher's Disclaimer: This is a PDF file of an unedited manuscript that has been accepted for publication. As a service to our customers we are providing this early version of the manuscript. The manuscript will undergo copyediting, typesetting, and review of the resulting proof before it is published in its final citable form. Please note that during the production process errors may be discovered which could affect the content, and all legal disclaimers that apply to the journal pertain.
} 
the regulation of insulin signalling and glucose homeostasis. We show that $\mathrm{Cul}^{-1-}$ mouse embryonic fibroblasts displayed enhanced AKT and Erk MAP kinase phosphorylation upon insulin stimulation. Depletion of CUL7 by RNA interference in C2C12 myotubes led to increased activation of insulin signalling pathways and cellular glucose uptake, as well as a reduced capacity of these cells to execute insulin-induced degradation of insulin receptor substrate 1 (IRS1). In vivo, heterozygosity of either $\mathrm{Cul7}$ or $\mathrm{Fbxw8}$, both key components of CRL7, resulted in elevated PI3 kinase / AKT activation in skeletal muscle tissue upon insulin stimulation when compared to wild-type controls. Finally, $\mathrm{Cul} 7^{+-}$or $\mathrm{Fbxw}^{+/-}$mice exhibited enhanced insulin sensitivity and plasma glucose clearance. Collectively, our findings point to a yet unrecognized role of CRL7 in insulin-mediated control of glucose homeostasis by restraining PI3 kinase / AKT activities in skeletal muscle cells.

\section{Keywords}

ubiquitin; E3 ubiquitin ligase; proteasome; insulin; cell signalling

\section{Introduction}

Diabetes mellitus is a major metabolic disorder affecting more than 285 million people worldwide (1). $90 \%$ of the patients suffer from type 2 diabetes, which is characterized by glucose intolerance, insulin resistance and defects in pancreatic insulin secretion (2). Insulin exerts its effects in target tissues by binding to insulin tyrosine kinase receptors, resulting in the recruitment and phosphorylation of insulin receptor substrate (IRS) proteins. In particular IRS1 and IRS2 were shown to play critical roles in insulin signalling by transmitting receptor stimulation to the activation of PI3 kinase/AKT and Erk MAPK pathways, which mediate the metabolic and mitogenic effects of insulin, respectively (3). In addition, activation of PI3 kinase also triggers the translocation of vesicles containing glucose transporter 4 (GLUT4) from intracellular storage pools to the cell membrane, thereby enabling uptake of glucose into the cell (4).

A major cause of insulin resistance and type 2 diabetes is thought to be dysfunctional regulation of cellular signal transduction downstream of the insulin receptor $(5,6)$. Several studies provided evidence for dysregulation of key signalling molecules, such as IRS1, IRS2 and AKT1, in insulin resistant cells and tissues due to altered transcriptional or posttranslational (such as ubiquitin-mediated proteasomal degradation) activities (7). Timely degradation of intracellular proteins by the ubiquitin-proteasome system (UPS) is a precisely controlled process that regulates a broad spectrum of fundamental cellular functions, ranging from cell cycle progression to signal transduction. Central to this process is the recognition of a substrate protein by an E3 ubiquitin ligase, a pivotal step for initiating the ubiquitination reaction that joins the target protein covalently with polyubiquitin chains, thereby leading to its degradation by the $26 \mathrm{~S}$ proteasome (8).

We have previously identified IRS1 as a proteolytic target of Cullin-RING E3 ubiquitin ligase 7 (CRL7), a multimeric enzyme composed of the scaffold protein Cullin7 (CUL7), the RING finger protein ROC1 and the SKP1-FBXW8 substrate targeting subunit (9-11). It was shown that CRL7 induced degradation of IRS1 is part of a negative feedback loop via mammalian target of rapamycin complex 1 (mTORC1) and p70 S6 kinase (S6K) activities to restrain PI3 kinase/AKT signalling upon activation of the insulin-like growth factor 1 (IGF-1) receptor $(9,10)$. Collectively, these studies provided experimental evidence for a novel role of CRL7 in IGF-1 signalling in vitro. Based on these observations, we sought to investigate whether CRL7 also contributes to the regulation of insulin signalling and evaluate its biological relevance in vivo. 


\section{Materials and Methods}

\subsection{Animals}

$\mathrm{Cul}^{+/-}$mice were generated by replacing exons 2-4 of the $\mathrm{Cul7}$ gene with a PGK-neo cassette as described in detail previously (9). $F b x w 8^{+/-}$mice were generated by injecting embryonic stem cells harboring a gene trap insertion in intron 3 of the $F b x w 8$ gene (Clone RRT057, BayGenomics gene-trap resource) into C57BL/6J blastocysts (12). The injected blastocystes were then transplanted into pseudopregnant females using standard protocols (13). A similar approach was used by DeCaprio and colleagues (14). Both strains were maintained on a hybrid 129/SvJ X C57BL/6 background. All experiments were performed with female $8-12$ week old mice that were kept on a 12 hour light/dark cycle with free access to food and water. All protocols were reviewed and approved by the Institutional Animal Care and Use Committee of Mount Sinai School of Medicine (New York, USA) and the State Government of Bavaria (Germany).

\subsection{Insulin Tolerance Tests}

For insulin tolerance tests (ITT), 6 hour fasted mice were intra-peritoneally injected with a bolus of human insulin at 0.75 units per $\mathrm{kg}$ of body weight (Novolin R; Novo Nordisk, Denmark) according to standard protocol (15). Control animals received an intra-peritoneal bolus of saline $(0.9 \% \mathrm{NaCl})$. Blood glucose levels were determined in tail vein blood at the indicated times ( 0 to $120 \mathrm{~min}$ ) with a glucometer (Aventis Pharma, Frankfurt, Germany).

\subsection{Insulin Signalling Studies in vivo}

For assessment of insulin signalling pathways in vivo, mice were fasted for 6 hours and intra-peritoneally injected with human insulin at 2 units per $\mathrm{kg}$ of body weight (Humalog, Lilly, Bad Homburg, Germany) or $0.9 \% \mathrm{NaCl}$ (control group). After 5 min mice were sacrificed by cervical dislocation and tissue collected. Gastrocnemius muscles were removed and snap frozen in liquid nitrogen. Tissues were homogenized in ice-cold lysis buffer (50 mM HEPES, pH 8.0, 5 mM EDTA, 15 mM NaPP tetrabasic, 25 mM NaF, 100 mM BGP, 2 $\mathrm{mM} \mathrm{Na} \mathrm{VO}_{4}, 0.1 \%$ Triton X-100 and phosphatase and protease inhibitors) using a motordriven ultra turrax (IKA, Staufen, Germany). Homogenates were centrifuged at 14,000 x g for $10 \mathrm{~min}$ at $4^{\circ} \mathrm{C}$, and supernatants stored at $-80^{\circ} \mathrm{C}$ until analysis.

\subsection{Insulin Signalling Studies in vitro}

For insulin signalling studies in vitro, mouse embryonic fibroblasts (MEFs) of $\mathrm{Cul7}^{-/-}$and $\mathrm{Cul}^{+/-}$embryos were isolated from pregnant mice at day 14.5 p.c. and grown in DMEM with $10 \%$ FCS as described previously (9). For analysis of signalling pathways, MEFs were serum starved for $16 \mathrm{~h}$ and stimulated with $100 \mathrm{nM}$ insulin for various time intervals. Cell extracts ( $50 \mu \mathrm{g}$ of protein) were separated by $10 \%$ SDS-PAGE followed by immunoblot analysis. Murine C2C12 myoblasts were obtained from ATCC (Wesel, Germany) and cultured in DMEM $(4,500 \mathrm{mg} / \mathrm{l}$ glucose $)$ containing $10 \%$ FCS. For differentiation to myotubes, medium was switched to DMEM with $2 \%$ horse serum for 7 to 10 days. For signalling experiments, C2C12 myotubes were transfected with CUL7 (On Target Plus SMART pool, Dharmacon, Colorado) or scramble siRNA for $48 \mathrm{~h}$ following the manufacturer's instructions. At $32 \mathrm{~h}$ post-transfection, $\mathrm{C} 2 \mathrm{C} 12$ myotubes were serum starved for $16 \mathrm{~h}$ before exposure to insulin $(100 \mathrm{nM})$ or DMEM (controls) for various time intervals $(15,30$ and $45 \mathrm{~min})$. For analysis of insulin triggered IRS1 degradation kinetics, C2C12 myotubes were serum deprived for four hours, treated with emetine $(10 \mu \mathrm{m})$ and stimulated with insulin $(100 \mathrm{nM})$ for various time intervals $(4,8$ and 16 hours). Cells were then washed in ice-cold PBS and lysed in buffer containing $20 \mathrm{mM}$ Tris- $\mathrm{HCl}$ (pH 8.0), $140 \mathrm{mM} \mathrm{NaCl}$, $1 \mathrm{mM} \mathrm{MgCl} 2,1 \mathrm{mM} \mathrm{CaCl}_{2}, 1 \mathrm{mM}$ dithiothreitol, $10 \%$ glycerol, $0.02 \mathrm{mM}$ p-amidino 
phenylmethanesulfonyl fluoride, $1 \%$ Nonidet ${ }^{\circledR} \mathrm{P}-40$ substitute, $0.5 \mathrm{mM} \mathrm{Na}_{3} \mathrm{VO}_{4}$ and $20 \mathrm{mM}$ $\mathrm{Na}_{4} \mathrm{P}_{2} \mathrm{O}_{7}$.

\subsection{Immunoblotting Analysis}

Lysate protein was resolved by SDS-PAGE and transferred to PVDF membranes (Bio-Rad Laboratories, Richmond). Phosphorylated and total proteins were identified by immunoblotting using the following primary antibodies: polyclonal anti-P-AKT (Ser473), anti-P-Erk (Thr202/Tyr204) and anti-AKT, monoclonal anti-Erk 1/2 (Cell Signaling, Danvers, MA); polyclonal anti-IRS1 (Millipore, Billerica, MA); monoclonal anti-CUL7 (Sigma-Aldrich, Steinheim, Germany) and anti-HSP90 a/ß (F-8) (Santa Cruz Biotechnology, Santa Cruz, CA). Secondary horseradish peroxidase-conjugated goat antimouse IgG and anti-rabbit IgG antibodies were from Cell Signalling (Danvers, MA).

\section{6. $2-\left[{ }^{3} \mathrm{H}\right]$ deoxy-D-glucose uptake assays}

To quantify cellular glucose influx upon insulin stimulation, 2-[3ㄱ] deoxy-D-glucose (2DOG) uptake measurements were carried out in $\mathrm{C} 2 \mathrm{C} 12$ myotubes according to standard protocol (16). Briefly, cells were incubated for $10 \mathrm{~min}$ in Krebs-Ringer buffer containing 2$\left[{ }^{3} \mathrm{H}\right]$ deoxy-D-glucose $(0.2 \mathrm{mCi} / \mathrm{ml})$ in the presence or absence of $100 \mathrm{nM}$ insulin.

Cytochalasin B $(20 \mu \mathrm{M})$ was used to block non-specific glucose uptake. Cells were lysed in PBS containing $0.2 \mathrm{M} \mathrm{NaOH}$ and radioactivity measured with a liquid scintillation counter (Packard, Canberra, Australia).

\subsection{Reagents}

Dulbecco's modified Eagle's medium (DMEM), fetal calf serum (FCS) and horse serum were from Pan-Biotech (Aidenbach, Germany). All other reagents used were of analytical grade from Sigma-Aldrich (Steinheim, Germany) or Applichem (Darmstadt, Germany).

\subsection{Statistical Analysis}

Results are expressed as mean \pm SD or SEM. Comparisons between groups were made by unpaired two-tailed Student's $t$ test or one-way analysis of variance (ANOVA), as appropriate. Statistical differences were determined using Prism GraphPad software (La Jolla, CA). For all analyses, $P$ values of $<0.05$ were considered statistically significant.

\section{Results}

\subsection{Loss of CUL7 is associated with hyper-activation of AKT and Erk in response to insulin}

We previously identified IRS1 as a substrate of CRL7 and demonstrated that mouse embryonic fibroblasts (MEFs) deficient of $\mathrm{Cul7}$ display hyper-activation of IRS1 downstream PI3K/AKT and Erk MAPK pathways upon IGF-1 stimulation (9). As both IGF-1 and insulin receptors utilize IRS1 for signal transduction (3), we sought to further investigate the effect of insulin receptor activation in $\mathrm{Cul7^{+/+ }}, \mathrm{Cul}^{+/-}$and $\mathrm{Cul7}^{-/-} \mathrm{MEFs}$. When compared to the $\mathrm{Cul7^{+/+ }}$ cells (Fig. 1A, lane 1-4), insulin stimulation for 15, 30 and 60 min resulted in enhanced activation and duration of PI3K/AKT (as evidenced by phosphorylation of AKT at S473) in $\mathrm{Cul}^{+/-}$(lanes 5-8) and to a higher extent in $\mathrm{Cul}^{-/-}$ MEFs (lanes 9-12). Activation of the Erk1/2 MAPK pathway (as evidenced by phosphorylation of Erk1/2 at Thr202/Tyr204, respectively) was moderately increased in $\mathrm{Cul7}^{-/-}$MEFs when compared to controls cells (Fig.1A, lanes 9-12 vs. 1-4). These results suggest that loss of $\mathrm{Cul7}$ in MEFs is associated with hyper-activation of signalling pathways downstream of the insulin receptor. To further corroborate these findings we employed murine $\mathrm{C} 2 \mathrm{C} 12$ myotubes, a well-established in vitro model for the study of insulin action 
(17). After differentiation of $\mathrm{C} 2 \mathrm{C} 12$ muscle progenitor cells to myotubes, siRNA directed against CUL7 mRNA (or scramble control) was transfected followed by immunoblot analyses. CUL7 knockdown efficacy was approx. 85\% (Fig. 1B and C). Upon exposure to insulin, CUL7-depleted C2C12 cells showed an enhanced phosphorylation of both AKT

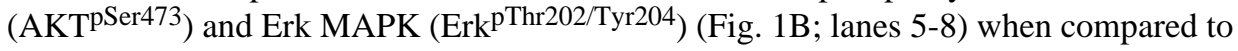
scramble siRNA treated cells (lanes 1-4). Collectively, these findings indicate that loss of CUL7 results in enhanced PI3K/AKT and Erk MAPK activation upon insulin stimulation, thereby supporting a role for CRL7 in the regulation of the cellular insulin signalling.

\subsection{Depletion of CUL7 impairs insulin-induced IRS1 degradation in $\mathrm{C} 2 \mathrm{C} 12$ myotubes}

Several previous studies have shown that chronic exposure of cells to insulin triggers the degradation of IRS1 by the 26S proteasome (18-21). To test if CRL7 participates in insulinmediated IRS1 degradation, CUL7 siRNA and control transfected C2C12 myotubes were treated with the ribosomal inhibitor emetine and chased with insulin for 4, 8 and $16 \mathrm{hrs}$. In accordance with a previous study (22), the half-life of IRS1 in C2C12 myotubes was less than 4 hours (Fig. 2, lanes 1-4). Insulin stimulation led to a significant reduction of IRS1 protein (lanes 5-7), which could be partially rescued by proteasomal inhibition with MG132 (lanes 8-10). Strikingly, CUL7 depletion resulted in a robust stabilization of IRS1 even after 16 hours of insulin treatment (lanes 11-14). These results suggest that CRL7 plays a central role for IRS1 proteasomal degradation during chronic insulin stimulation in $\mathrm{C} 2 \mathrm{C} 12$ myotubes.

\subsection{Enhanced glucose uptake upon CUL7 depletion in vitro}

In skeletal muscle cells, binding of insulin to its receptor triggers PI3 kinase-mediated translocation of GLUT4 glucose transport proteins from intracellular vesicles to the cell membrane, enabling the uptake of glucose from the plasma (4). To determine whether the observed hyper-activation of the PI3K/AKT pathway in CUL7-depleted C2C12 myotubes impacts on cellular glucose influx, 2-deoxy-D- $\left({ }^{3} \mathrm{H}\right)$-glucose (2-DOG) uptake assays were performed. As shown in Fig. 3, CUL7 depletion resulted in a significant increase of 2-DOG uptake upon insulin stimulation when compared to scramble siRNA-treated control cells (6.4\% vs. 27.8\%; $P=0.002$ ). These results indicate that inactivation of CRL7 in C2C12 myotubes facilitates insulin-triggered glucose influx. In summary, the in vitro experiments in MEFs and C2C12 cells provide evidence that loss of CUL7 leads to increased activation of insulin signalling pathways and cellular glucose uptake, as well as diminished capacity of these cells to execute insulin-induced degradation of IRS1.

\subsection{CRL7 haploinsufficiency is associated with enhanced insulin-dependent AKT pathways in skeletal muscle tissue of $\mathrm{Cul}^{+/-}$or $\mathrm{Fbxw8}^{+/-}$mice}

Given the above in vitro data linking CRL7 to insulin signalling, we next studied skeletal muscle tissue of heterozygous $\mathrm{Cul7}$ or $\mathrm{Fbxw8}$-deficient mice to assess a potential role for this E3 ligase in insulin signalling and glucose homeostasis in vivo. Skeletal muscle is responsible for $70-90 \%$ of insulin-stimulated glucose disposal $(23,24)$ and expresses high transcript levels of $C U L 7$ (25). For in vivo insulin signalling studies, only heterozygous CRL7-deficient mice were available to us because homozygous deletion of $\mathrm{Cul7}$ resulted in perinatal lethality as described previously $(9,26)$. We obtained no homozygous $F b x w 8^{-/-}$ offspring from a total of 223 mice generated, which yielded $36 \mathrm{Fbxw}^{+/+}$and $187 \mathrm{Fbxw} 8^{+/-}$. Cul7 and Fbxw 8 heterozygous mice were food deprived for 6 hours and insulin or saline was injected intra-peritoneally. After $5 \mathrm{~min}$, mice were sacrificed and gastrocnemius muscle snap frozen in liquid nitrogen and tissue lysates subjected to immunoblot analyses for activated $\mathrm{PI} 3 \mathrm{~K} / \mathrm{AKT}$ as the predominant signalling pathway regulating glucose uptake (27). Insulin application resulted in an approx. 3.5-fold increase of AKT activation (as evidenced by 
pS473 phosphorylation) in both $\mathrm{Cull}^{+/+}$and $\mathrm{Fbxw}^{+/+}$mice when compared to saline controls (Fig. 4 A and B; lanes 4-6 vs. 1-3).

In contrast, AKT pS473 phosphorylation was markedly increased in $\mathrm{Cul7^{+/ }}$ mice (5.8-fold, $P<0.001)$ and $F b x w 8^{+/-}$mice (9.1-fold, $\left.P<0.001\right)$ when compared to saline treated $\mathrm{Cul}^{+/+}$and $\mathrm{Fbxw}^{+/+}$mice, respectively (Fig. $4 \mathrm{~A}$ and B; lanes 10-12 vs. 1-3). In addition, the increment of pS473 phosphorylation upon insulin stimulation was significantly higher in both $\mathrm{Cul7^{+- }}$ and $\mathrm{Fbxw} 8^{+/-}$mice (Fig. $4 \mathrm{~A}$ and B; lanes 10-12) when compared to insulintreated $\mathrm{Cull}^{+/+}$and $\mathrm{Fbxw}^{+/+}$mice (lanes 4-6), respectively $(P<0.01$ and $P<0.05)$. Of note, similar results were obtained with antibodies directed against AKT pT308 (data not shown). Thus, CRL7 haploinsufficiency results in hyper-activation of the PI3K/AKT pathway upon insulin stimulation.

\subsection{Cul7 $7^{+/-}$or Fbxw8 $8^{+/-}$mice display enhanced clearance of blood glucose in response to insulin}

We next investigated physiological relevance of CRL7-mediated insulin signal pathway modulation for glucose homeostasis in vivo. To this end, insulin tolerance tests (ITT), a well established method for the estimation of in vivo insulin action (28), were performed with $\mathrm{Cul7}$ and $\mathrm{Fbxw8}$-heterozygous mice, respectively.

Baseline plasma glucose concentration of $\mathrm{Cul}^{+/+}$mice was $141 \mathrm{mg} / \mathrm{dl}(+/-6.3 \mathrm{mg} / \mathrm{dl})$ and $134 \mathrm{mg} / \mathrm{dl}(+/-6.5 \mathrm{mg} / \mathrm{dl})$ for $\mathrm{Cul7^{+/- }}$ mice. $60 \mathrm{~min}$ after intra-peritoneal application of 0.75 $\mathrm{U} / \mathrm{kg}$ body weight insulin, the $\mathrm{Cul7}^{+/+}$mice displayed a decline of plasma glucose level to $90 \mathrm{mg} / \mathrm{dl}(+/-12.0 \mathrm{mg} / \mathrm{dl})$ whereas $\mathrm{Cul}^{+/-}$mice showed an exaggerated decline $(49 \mathrm{mg} / \mathrm{dl}$ $+/-10.2 \mathrm{mg} / \mathrm{dl}$ ), corresponding to a decrease by $43 \%$ and $63 \%$, respectively (Fig. $5 \mathrm{~A}$ ). In line with these findings, the integrated area under the curve (AUC) of blood glucose measurements was significantly smaller in $\mathrm{Cull}^{+/-}$mice when compared to $\mathrm{Cul7^{+/+ }}$ mice (Fig. 5B; $P=0.007$ ).

Similar results were obtained with the $F b x w 8$ haploinsufficiency model. Baseline blood glucose levels after 6 hour fasting of $F b x w 8^{+/+}$or $\mathrm{Fbxw}^{+/-}$mice were $142 \mathrm{mg} / \mathrm{dl}(+/-7.9$ $\mathrm{mg} / \mathrm{dl})$ and $130 \mathrm{mg} / \mathrm{dl}(+/-6.0 \mathrm{mg} / \mathrm{dl})$, respectively. The results of the ITT revealed that the blood glucose levels decreased more rapidly in $F b x w 8$ heterozygous than in the wild-type mice. After $60 \mathrm{~min}$, blood glucose levels were decreased by $~ 68 \%$ to $46 \mathrm{mg} / \mathrm{dl}(+/-4.7 \mathrm{mg} /$ $\mathrm{dl})$ in the $\mathrm{Fbxw} 8^{+/+}$and by $\sim 77 \%$ to $30 \mathrm{mg} / \mathrm{dl}(+/-3.5 \mathrm{mg} / \mathrm{dl})$ in $\mathrm{Fbxw} 8^{+/-}$mice, respectively (Fig. $5 \mathrm{C}$ ). Integration of AUC demonstrated a significantly higher glucose clearance of $F b x w 8^{+/-}$compared to $F b x w 8^{+/+}$mice (Fig. 5D; $P<0.05$ ).

Taken together, these data indicate that loss of either a $\mathrm{Cul7}$ or $F b x w 8$ allele results in enhanced clearance of blood glucose in response to insulin in vivo.

\section{Discussion}

In this study we provide both in vitro and in vivo evidence for a regulatory role of CRL7 in regulation of insulin signalling and glucose homeostasis. We show that $\mathrm{Cul7^{-I- }}$ mouse embryonic fibroblasts displayed an increase in the activation of AKT and Erk phosphorylation upon insulin stimulation. Depletion of CUL7 by siRNA in C2C12 myotubes led to enhanced activation of downstream pathways of the insulin receptor, cellular glucose uptake upon insulin stimulation, and impaired insulin-triggered proteasomal degradation of IRS1. Finally, by using two different CRL7 haploinsufficiency mouse models $\left(\mathrm{Cull}^{+/-}\right.$and $\mathrm{Fbxw} 8^{+/-}$mice), we demonstrated that loss of either a $\mathrm{Cul7}$ or $\mathrm{Fbxw} 8$ allele resulted in hyper-activation of the PI3K/AKT signalling pathway upon insulin stimulation in skeletal muscle and plasma glucose clearance in vivo. 
Our previous work demonstrated a role for CRL7 in targeting IRS1 for proteasomal degradation in the context of IGF-1 signalling (9). Ablation of $\mathrm{Fbxw8}$ and $\mathrm{Cul7}$, respectively, led to an accumulation of IRS1 and resulted in increased activation of IRS1 downstream pathways upon IGF-1 stimulation. Because IRS1 is a nodal point shared by IGF-1 and insulin receptors, we continued to investigate in the present study the effects of CRL7 on insulin signalling. Sun et al. (20) first showed that degradation of IRS1 during prolonged exposure to insulin is controlled by the UPS. We observed that chronic insulin stimulation for 4-16 hours in $\mathrm{C} 2 \mathrm{C} 12$ myotubes resulted in IRS1 proteolysis which was prevented by either MG132 treatment or siRNA directed against CUL7 (Fig. 2). These results indicate that CRL7 is critically involved in insulin-triggered IRS1 regulation in skeletal muscle-derived cells. Of note, a number of additional E3 ubiquitin ligases have been reported to contribute to the regulation of IRS1 stability. SOCS1 and 3 were shown to promote the degradation of IRS proteins, which may be involved in inflammation-induced insulin resistance, suggesting a role for CUL5 in targeting IRS1 for degradation (29). The Cbl-b RING E3 ligase was shown to degrade IRS1 during states of muscle atrophy (30). A recent report by Glass and co-workers identified the muscle-specific SCF Fbxo40 as an E3 ligase responsible for IRS1 degradation upon IGF-1 stimulation (22). Fbxo40 was upregulated during muscle differentiation and Fbxo40 knockdown rescued IGF-1 induced proteolysis of IRS1. Whether and how these E3s contribute to control insulin signalling remain to be defined.

We observed that $\mathrm{C} 2 \mathrm{C} 12$ cells depleted of CUL7 (Fig. 1) and muscle tissue of mice heterozygous for either $\mathrm{Cul7}$ or $\mathrm{Fbxw} 8$ (Fig. 4) displayed enhanced activation of IRS1 downstream signalling pathways upon insulin stimulation, thus suggesting a regulatory role for CRL7 in insulin signalling on the cellular and tissue level. Mechanistically, several lines of evidence have indicated that IRS1 protein homeostasis is regulated by a negative feedback loop via mTOR and its effector kinase S6K. Initial evidence for a negative feedback loop stems from mice heterozygous for tuberous sclerosis 2 (TSC2) in the context of tumor suppression (31). TSC2 is an inhibitor of ras homologue enriched in brain (RHEB) and hence the loss of TSC2 leads to activation of mTOR/S6K. It was shown that $T s c 2^{+/-}$ mice develop benign tumors due to suppressed PI3K/AKT that resulted from enhanced mTOR/S6K induced IRS1 degradation (31). In the context of insulin signalling, Haruta et al. have initially observed that IRS1 degradation upon insulin exposure requires PI3K and mTORC1, as IRS1 down-regulation was sensitive to treatment with the PI3K inhibitor wortmannin and the mTORC1 inhibitor rapamycin (19). Further, it was shown that CRL7IRS1 interaction and CRL7 mediated degradation of IRS1 depends on mTOR/S6K activity $(9,10)$, reviewed in (32). In addition, Stahl and co-workers identified the hominoid-specific protein TBC1D3 as a repressor of IRS1 ubiquitination and degradation of IRS1 via combined inhibitory action of TBC1D3 and PP2A on S6K (33). Taken together, these data suggest that disruption of mTORC1/S6K feedback control via CRL7 is at least in part responsible for hyper-activated insulin signalling in cells devoid of CRL7 function.

In addition, work by Jacinto and co-workers has demonstrated a novel role for the rapamycin-insensitive mTOR complex 2 (mTORC2) in CRL7 mediated IRS1 degradation (34). mTORC2 was shown to phosphorylate Fbxw8 on Ser86 resulting in increased Fbxw8 stability, leading to reduced IRS1 proteins levels. Thus, both mTORC1 and mTORC2 appear to contribute to the regulation of insulin signalling via CRL7 mediated IRS1 degradation and underscore a central role played by CRL7 within the mTOR-S6K-IRS1 axis of insulin signalling.

In the present study, loss of CRL7 functionality in C2C12 myotubes (Fig. 3) and heterozygous knockout mice for either $\mathrm{Cul7}$ or $\mathrm{Fbxw} 8$ (Fig. 5) resulted in enhanced glucose uptake and insulin induced plasma glucose clearance, respectively. These results support a 
model in which CRL7 contributes to the regulation of glucose homeostasis and energy metabolism on both the cellular and organismal level. The mTORC1/S6K-IRS1 feedback loop has been suggested to directly contribute to the pathogenesis of diabetes. It was shown that hyper-activation of mTORC1 caused by overfeeding in mice resulted in insulin desensitization via mTORC1/S6K1-IRS1 feedback signalling (35). In addition, downregulation of IRS1 suppressed PI3 kinase / AKT activity, causing a reduction of glucose uptake and glycogen synthesis in liver and muscle, as well as increase of gluconeogenesis and glucose release by the liver. In further support of the role of the mTORC1/S6K1-IRS1 feedback loop in the pathogenesis of type 2 diabetes, S6K1-deficient mice displayed enhanced insulin sensitivity when chronically maintained on a high fat diet (35). Of note, Zou and co-workers have recently identified liver kinase B1 (LKB1), a central regulator of energy metabolism, as novel regulator of CRL7 and CRL7-mediated IRS1 degradation (36). LKB1 deletion resulted in elevated Fbxw8 protein level via AMP-activated protein kinase (AMPK) and SRE binding protein 1c (SREBP-1c) mediated activation of the Fbxw8 gene transcription, resulting in increased IRS1 degradation. This is of particular interest, as it was shown that LKB1 is required for repression of mTOR under low ATP conditions in an AMPK- and TSC2 dependent manner (37).

However, further exploration of the precise role of CRL7 in the regulation in glucose homeostasis and energy metabolism will require in-depth metabolic profiling and analyses. In addition, it will be important to determine whether inhibition of CRL7 can protect from diet-induced obesity, e.g. in high fat diet models. Delineating these metabolic functions of CRL7 will pave the way towards the development of novel therapeutic strategies to modulate insulin sensitivity for the treatment of insulin resistance and type 2 diabetes.

\section{Acknowledgments}

This work was supported by research grant SA 1706/3-1 from the German Research Foundation (to A.S.) and Marie Curie International Reintegration grant 256584 (to A.S.). Z.-Q. P. was supported by US Public Health Service grants GM61051 and CA095634. We thank Milena Dürbaum for optimizing the IRS1 degradation assay in C2C12 myotubes.

\section{References}

1. Shaw JE, Sicree RA, Zimmet PZ. Global estimates of the prevalence of diabetes for 2010 and 2030. Diabetes Res. Clin. Pract. 2010; 87:4-14. [PubMed: 19896746]

2. Nolan CJ, Damm P, Prentki M. Type 2 diabetes across generations: from pathophysiology to prevention and management. Lancet. 2011; 378:169-181. [PubMed: 21705072]

3. White MF. IRS proteins and the common path to diabetes. Am J Physiol Endocrinol Metab. 2002; 283:413-422.

4. Charron MJ, Katz EB, Olson AL. GLUT4 gene regulation and manipulation. J. Biol. Chem. 1999; 274:3253-3256. [PubMed: 9920861]

5. Biddinger SB, Kahn CR. From mice to men: insights into the insulin resistance syndromes. Annu. Rev. Physiol. 2006; 68:123-158. [PubMed: 16460269]

6. Taniguchi CM, Emanuelli B, Kahn CR. Critical nodes in signalling pathways: insights into insulin action. Nat. Rev. Mol. Cell Biol. 2006; 7:85-96. [PubMed: 16493415]

7. Wing SS. The UPS in diabetes and obesity. BMC Biochem. 2008; 9(Suppl 1):S6. [PubMed: 19007436]

8. Hershko A, Ciechanover A. The ubiquitin system. Annu Rev Biochem. 1998; 67:425-479. [PubMed: 9759494]

9. Xu X, Sarikas A, Dias-Santagata DC, Dolios G, Lafontant PJ, Tsai S-C, Zhu W, Nakajima H, Nakajima HO, Field LJ, Wang R, Pan Z-Q. The CUL7 E3 ubiquitin ligase targets insulin receptor substrate 1 for ubiquitin-dependent degradation. Mol. Cell. 2008; 30:403-414. [PubMed: 18498745] 
10. Xu X, Keshwani M, Meyer K, Sarikas A, Taylor S, Pan Z-Q. Identification of insulin receptor substrate 1's degradation determinants for signalling cullin-RING E3 ubiquitin ligase 7-mediated ubiquitination. J. Biol. Chem. 2012; 287:40758-40766. [PubMed: 23045529]

11. Sarikas A, Hartmann T, Pan Z-Q. The cullin protein family. Genome Biol. 2011; 12:220. [PubMed: 21554755]

12. Stryke D, Kawamoto M, Huang CC, Johns SJ, King LA, Harper CA, Meng EC, Lee RE, Yee A, L'Italien L, Chuang P-T, Young SG, Skarnes WC, Babbitt PC, Ferrin TE. BayGenomics: a resource of insertional mutations in mouse embryonic stem cells. Nucleic Acids Res. 2003; 31:278-281. [PubMed: 12520002]

13. Hogan, B.; Beddington, R.; Costantini, F. Manipulating the mouse embryo: A laboratory manual. Second. Cold Spring Harbor Laboratory; 1994.

14. Tsutsumi T, Kuwabara H, Arai T, Xiao Y, Decaprio JA. Disruption of the Fbxw8 gene results in pre- and postnatal growth retardation in mice. Mol. Cell. Biol. 2008; 28:743-751. [PubMed: 17998335]

15. Gelling RW, Du XQ, Dichmann DS, Romer J, Huang H, Cui L, Obici S, Tang B, Holst JJ, Fledelius C, Johansen PB, Rossetti L, Jelicks LA, Serup P, Nishimura E, Charron MJ. Lower blood glucose, hyperglucagonemia, and pancreatic alpha cell hyperplasia in glucagon receptor knockout mice. Proc. Natl. Acad. Sci. U.S.A. 2003; 100:1438-1443. [PubMed: 12552113]

16. Dransfeld O, Uphues I, Sasson S, Schürmann A, Joost HG, Eckel J. Regulation of subcellular distribution of GLUT4 in cardiomyocytes: Rab4A reduces basal glucose transport and augments insulin responsiveness. Exp. Clin. Endocrinol. Diabetes. 2000; 108:26-36. [PubMed: 10768829]

17. Schmitz-Peiffer C, Craig DL, Biden TJ. Ceramide generation is sufficient to account for the inhibition of the insulin-stimulated PKB pathway in C2C12 skeletal muscle cells pretreated with palmitate. J. Biol. Chem. 1999; 274:24202-24210. [PubMed: 10446195]

18. Boura-Halfon S, Shuster-Meiseles T, Beck A, Petrovich K, Gurevitch D, Ronen D, Zick Y. A novel domain mediates insulin-induced proteasomal degradation of insulin receptor substrate 1 (IRS-1). Mol. Endocrinol. 2010; 24:2179-2192. [PubMed: 20843941]

19. Haruta T, Uno T, Kawahara J, Takano A, Egawa K, Sharma PM, Olefsky JM, Kobayashi M. A rapamycin-sensitive pathway down-regulates insulin signalling via phosphorylation and proteasomal degradation of insulin receptor substrate-1. Mol. Endocrinol. 2000; 14:783-794. [PubMed: 10847581]

20. Sun XJ, Goldberg JL, Qiao LY, Mitchell JJ. Insulin-induced insulin receptor substrate-1 degradation is mediated by the proteasome degradation pathway. Diabetes. $1999 ; 48: 1359-1364$. [PubMed: 10389839]

21. Pederson TM, Kramer DL, Rondinone CM. Serine/threonine phosphorylation of IRS-1 triggers its degradation: possible regulation by tyrosine phosphorylation. Diabetes. 2001; 50:24-31. [PubMed: 11147790]

22. Shi J, Luo L, Eash J, Ibebunjo C, Glass DJ. The SCF-Fbxo40 complex induces IRS1 ubiquitination in skeletal muscle, limiting IGF1 signalling. Dev. Cell. 2011; 21:835-847. [PubMed: 22033112]

23. DeFronzo RA, Jacot E, Jequier E, Maeder E, Wahren J, Felber JP. The effect of insulin on the disposal of intravenous glucose. Results from indirect calorimetry and hepatic and femoral venous catheterization. Diabetes. 1981; 30:1000-1007. [PubMed: 7030826]

24. Shulman GI, Rothman DL, Jue T, Stein P. Quantitation of muscle glycogen synthesis in normal subjects and subjects with non-insulin-dependent diabetes by $13 \mathrm{C}$ nuclear magnetic resonance spectroscopy. N Engl J Med. 1990; 322:223-228. [PubMed: 2403659]

25. Huber C, Dias-Santagata D, Glaser A, O’Sullivan J, Brauner R, Wu K, Xu X, Pearce K, Wang R, Uzielli ML, Dagoneau N, Chemaitilly W, Superti-Furga A, Santos, Dos H, Megarbane A, Morin G, Gillessen-Kaesbach G, Hennekam R, Van der Burgt I, Black GC, Clayton PE, Read A, Le Merrer M, Scambler PJ, Munnich A, Pan ZQ, Winter R, Cormier-Daire V. Identification of mutations in CUL7 in 3-M syndrome. Nat. Genet. 2005; 37:1119-1124. [PubMed: 16142236]

26. Arai T, Kasper JS, Skaar JR, Ali SH, Takahashi C, DeCaprio JA. Targeted disruption of p185/Cul7 gene results in abnormal vascular morphogenesis. Proc. Natl. Acad. Sci. U.S.A. 2003; 100:98559860. [PubMed: 12904573] 
27. Saltiel AR, Kahn CR. Insulin signalling and the regulation of glucose and lipid metabolism. Nature. 2001; 414:799-806. [PubMed: 11742412]

28. Stenbit AE, Tsao TS, Li J, Burcelin R, Geenen DL, Factor SM, Houseknecht K, Katz EB, Charron MJ. GLUT4 heterozygous knockout mice develop muscle insulin resistance and diabetes. Nat. Med. 1997; 3:1096-1101. [PubMed: 9334720]

29. Rui L, Yuan M, Frantz D, Shoelson S, White MF. SOCS-1 and SOCS-3 block insulin signalling by ubiquitin-mediated degradation of IRS1 and IRS2. J. Biol. Chem. 2002; 277:42394-42398. [PubMed: 12228220]

30. Nakao R, Hirasaka K, Goto J, Ishidoh K, Yamada C, Ohno A, Okumura Y, Nonaka I, Yasutomo K, Baldwin KM, Kominami E, Higashibata A, Nagano K, Tanaka K, Yasui N, Mills EM, Takeda $\mathrm{S}$, Nikawa T. Ubiquitin ligase Cbl-b is a negative regulator for insulin-like growth factor 1 signalling during muscle atrophy caused by unloading. Mol. Cell. Biol. 2009; 29:4798-4811. [PubMed: 19546233]

31. Manning BD, Logsdon MN, Lipovsky AI, Abbott D, Kwiatkowski DJ, Cantley LC. Feedback inhibition of AKT signalling limits the growth of tumors lacking Tsc2. Genes Dev. 2005; 19:1773-1778. [PubMed: 16027169]

32. Mieulet V, Lamb RF. Shooting the messenger: CULLIN' insulin signalling with Fbw8. Dev. Cell. 2008; 14:816-817. [PubMed: 18539111]

33. Wainszelbaum MJ, Liu J, Kong C, Srikanth P, Samovski D, Su X, Stahl PD. TBC1D3, a hominoid-specific gene, delays IRS-1 degradation and promotes insulin signalling by modulating p70 S6 kinase activity. PLoS ONE. 2012; 7:e31225. [PubMed: 22348058]

34. Kim SJ, DeStefano MA, Oh WJ, Wu C-C, Vega-Cotto NM, Finlan M, Liu D, Su B, Jacinto E. mTOR complex 2 regulates proper turnover of insulin receptor substrate-1 via the ubiquitin ligase subunit Fbw8. Mol. Cell. 2012; 48:875-887. [PubMed: 23142081]

35. Um SH, Frigerio F, Watanabe M, Picard F, Joaquin M, Sticker M, Fumagalli S, Allegrini PR, Kozma SC, Auwerx J, Thomas G. Absence of S6K1 protects against age- and diet-induced obesity while enhancing insulin sensitivity. Nature. 2004; 431:200-205. [PubMed: 15306821]

36. Zhang W, Wang Q, Song P, Zou M-H. Liver kinase b1 is required for white adipose tissue growth and differentiation. Diabetes. 2013; 62:2347-2358. [PubMed: 23396401]

37. Shaw RJ, Bardeesy N, Manning BD, Lopez L, Kosmatka M, DePinho RA, Cantley LC. The LKB1 tumor suppressor negatively regulates mTOR signalling. Cancer Cell. 2004; 6:91-99. [PubMed: $15261145]$ 


\section{Highlights}

- Dysfunctional insulin signaling is a major cause of insulin resistance and type 2 diabetes.

- Loss of Cullin-RING E3 ubiquitin ligase 7 (CRL7) results in enhanced activation of the insulin signaling pathway in vivo and in vitro

- we report CRL7 as a novel regulator of insulin signaling.

- CRL7 might constitute a novel pharmacological target for the treatment of type 2 diabetes. 
A

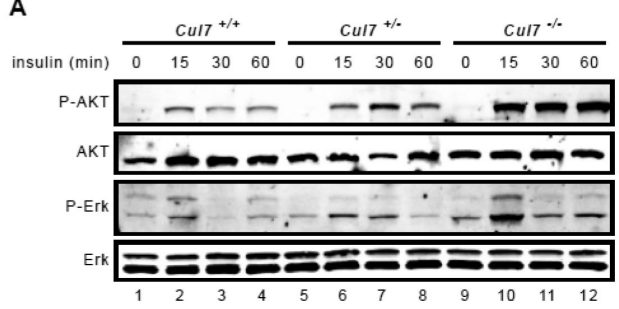

B

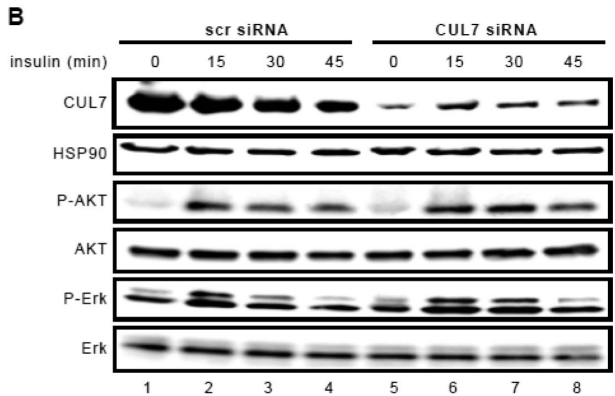

C
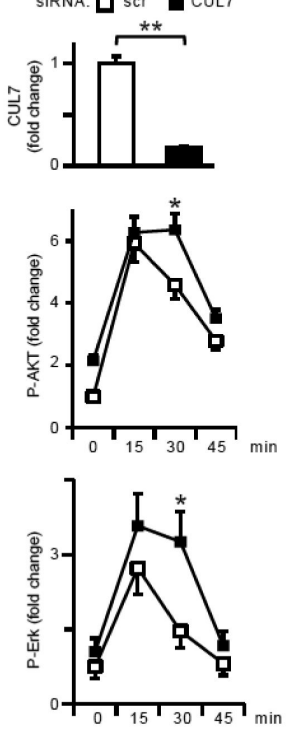

Fig. 1. Loss of CUL7 in mouse embryonic fibroblasts or $\mathrm{C2C12}$ myotubes results in enhanced insulin-dependent activation of AKT and Erk MAPK signalling

A. Fibroblasts of $\mathrm{Cul7}^{+/+}, \mathrm{Cul7^{+/- }}$ and $\mathrm{Cul7}^{-/-}$embryos at stage E14.5 were isolated and cultured for 2 to 4 passages prior to immunoblot analyses. After 16 hours of serum deprivation (0.2\% FCS), MEFs were stimulated with insulin (100 nM) for 15, 30 and 60 min and subjected to SDS-PAGE and immunoblotting for activated AKT $\left(\mathrm{AKT}^{\mathrm{pS} 473}\right)$ and

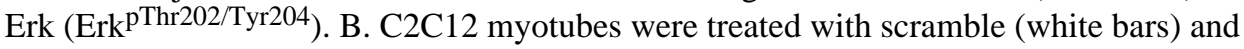
CUL7 (black bars) siRNA for $48 \mathrm{~h}$, serum starved and treated with $100 \mathrm{nM}$ insulin for the indicated time intervals. Cell lysates were analyzed by immunoblotting and HSP90 used as internal loading control. C. Quantification of CUL7 protein level and activation status of AKTpS473 and ErkpThr202/Tyr204 upon insulin stimulation in si-scr and si-CUL7 treated C2C12 myotubes. The graphs depict the results of four independent experiments. ${ }^{*} P<0.05$. Data are shown as fold change and expressed as mean \pm SD. 


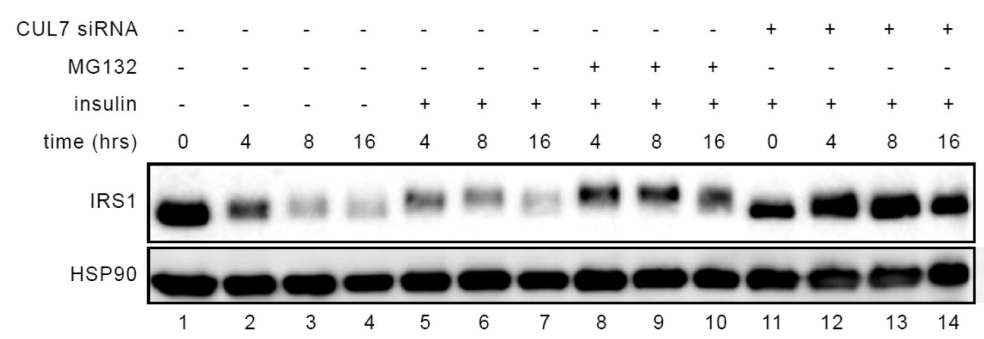

Fig. 2. Depletion of CUL7 in C2C12 myotubes impairs insulin triggered IRS1 degradation C2C12 myotubes were transfected with CUL7 siRNA or control as described above, serum deprived and treated with the protein synthesis inhibitor emetine $(10 \mu \mathrm{M})$. Cells in lanes 5 -14 were stimulated with insulin $(100 \mathrm{nM})$, cells in lane $8-10$ with insulin $(100 \mathrm{nM})$ and the proteasome inhibitor MG132 $(10 \mu \mathrm{M})$ for the indicated time intervals. Representative blot of four independent experiments. 


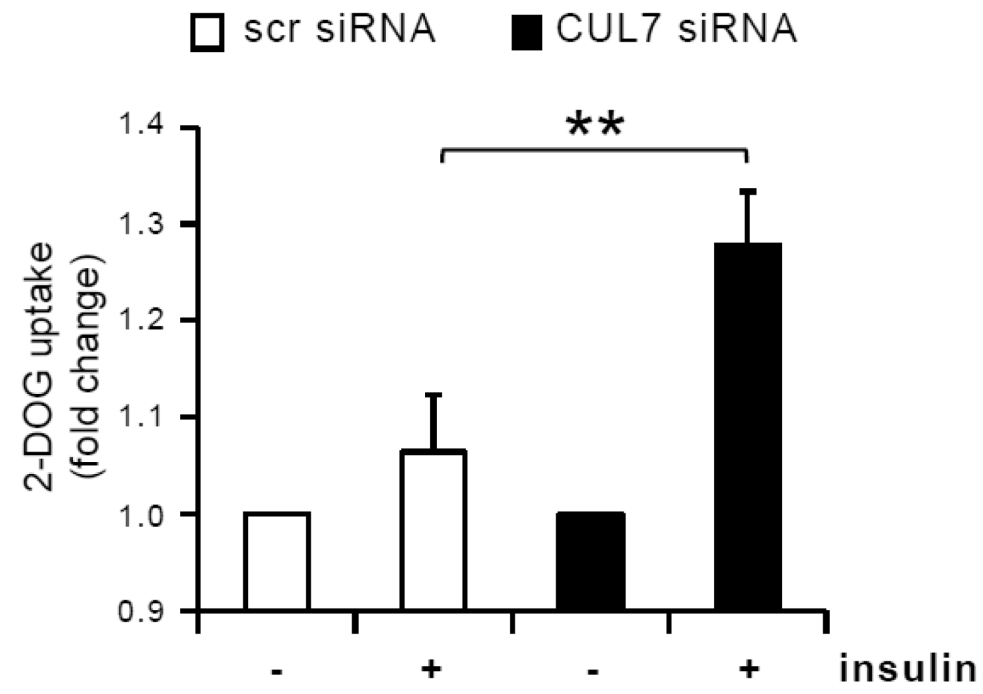

Fig. 3. Enhanced glucose uptake in C2C12 myotubes depleted of CUL7

C2C12 myotubes were treated with siRNA against scramble (white bars) or CUL7 (black bars) for 48 hours, serum deprived and the uptake of radioactive labeled 2-deoxy-D- $\left({ }^{3} \mathrm{H}\right)$ glucose (2-DOG) measured under basal conditions and after insulin (100 nM) stimulation for 30 min. $* * P=0.002 ; \mathrm{N}=4$. Data are shown as fold increase of 2-DOG uptake normalized to unstimulated controls at $0 \mathrm{~min}$ and expressed as mean $\pm \mathrm{SD}$. 
A

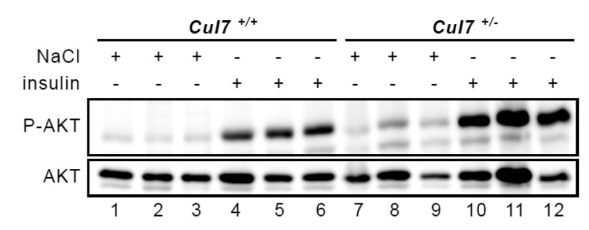

B

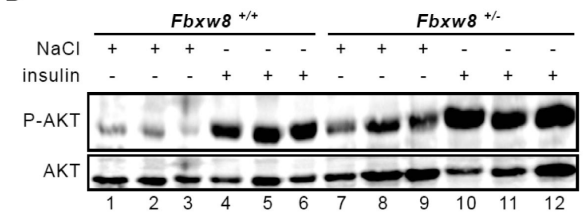

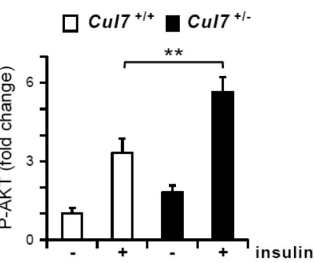

$\square$ Fbxw8 $8^{+/+}$Fbxw $^{+1 .}$

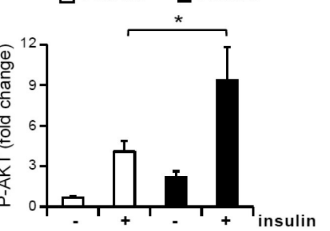

Fig. 4. Skeletal muscle tissue derived from Cul7 or Fbxw8-deficient mice displays enhanced AKT phosphorylation upon insulin stimulation

Mice were fasted for 6 hours and insulin or saline injected intra-peritoneally. At 5 min after injection, mice were sacrificed, gastrocnemius muscle snap frozen in liquid nitrogen and tissue lysates subjected to immunoblot analyses for activated AKTpS473. A. Comparison of $\mathrm{Cul7}^{+/+}$(lanes 1-6; white bars) and $\mathrm{Cul}^{+/-}$mice (lanes 7-12; black bars). B. Comparison of Fbxw $8^{+/+}$(lanes 1-6; white bars) and $F b x w 8^{+/-}$mice (lanes 7-12; black bars). The graph depicts the fold change normalized to unstimulated wild-type controls. Representative blots of four independent experiments. $* P<0.05$, ** $P<0.01$. Data are shown as fold change normalized to 0 min controls and expressed as mean \pm SD. 
A

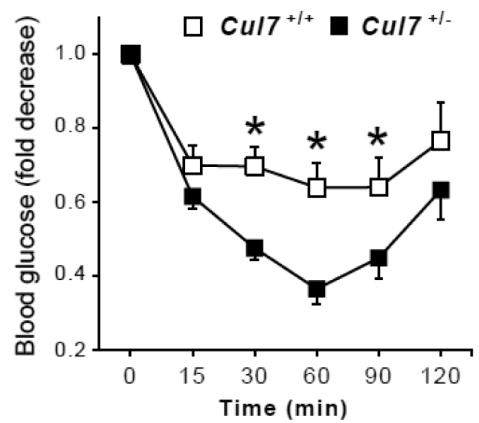

C

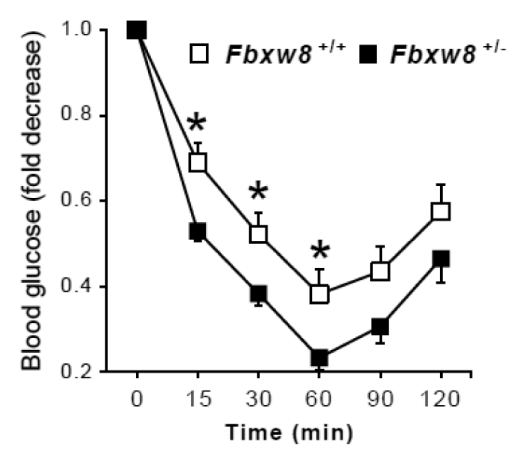

B

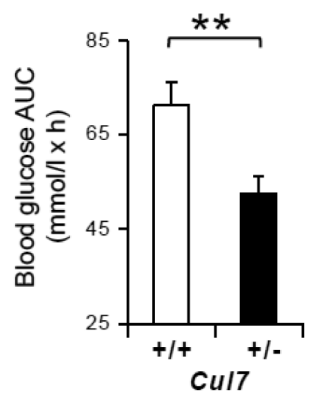

D

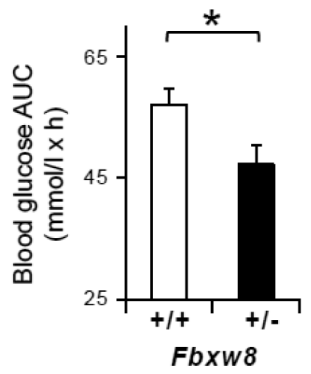

Fig. 5. Insulin tolerance tests reveal enhanced blood glucose clearance of $\mathrm{Cul}^{+/-}$and $\mathrm{Fbxw8}^{+/-}$ compared to $\mathrm{Cul} 7^{+/+}$and $\mathrm{Fbxw8}^{+/+}$mice

Plasma glucose level in 6 hour fasted mice following intra-peritoneal administration of 0.75 units of insulin $/ \mathrm{kg}$ of body weight ( $\mathrm{n}=8-10$ per group). A. Comparison of $\mathrm{Cul7}^{+/+}$(white squares) and $\mathrm{Cul7^{+/- }}$ (black squares) mice. B. Area under the curve for ITT of $\mathrm{Cul7}^{+/+}$ (white bar) and $\mathrm{Cul7}^{+/-}$mice (black bar). C. Comparison of $\mathrm{Fbxw8^{+/+ }}$ (white squares) and $F b x w 8^{+/-}$mice (black squares). D. Area under the curve for ITT of $F b x w 8^{+/+}$(white bar) and $\mathrm{Fbxw} 8^{+/-}$mice (black bar). $*$ Data are expressed as mean $\pm \mathrm{SEM}, * P<0.05, * * P=$ 0.007 . 